Journal of Contemporary Educational

Research Article

\title{
The Dilemma of the Times and the Remolding of the Way of Model Education
}

\author{
Xiaojuan Wang \\ Ningxia Medical University, Yinchuan 750021, Ningxia province, China
}

\begin{abstract}
As a general method of ideological and political education, model education has played an irreplaceable role in Chinese history. But in this pluralistic social background, it has been questioned and misinterpreted by more and more people, and the role model of traditional model education is gradually weakening. Model Education contributes to the construction of a harmonious socialist society and is an important channel to promote the all-round development of human beings and realize the harmony of interpersonal relations. Combing the theory of model education, endowing it with new connotation of the times, analyzing the situation of the current development and reshaping the new educational path, it plays an inestimable role in the development of individuals and society, it also contributes to the innovation of ideological and political education methods and provides a reference for the overall development of model education.
\end{abstract}

Key words: Model Education Method; Dilemma; Path reshaping

Publication date: September, 2020

Publication online: 30 September, 2020

*Corresponding author: Xiaojuan Wang, wxjwwj506@163.com

Example education method is an indispensable method in ideological and political education method, through setting up "example", propagandizing and learning model character, thus improving individual quality and social atmosphere. Because "model" the specific vivid image and the model of the advanced, so that the model has a strong appeal and credibility, can play the role of leading and inspiring others. Of course, the model education method is not with the development of the Internet and the enhancement of human autonomy and decline, so it is inevitable to carry out innovation, adapt to the development of the Times. It's the only way to stay alive. With the development of market economy, people's values and ways of life have changed. The traditional role model has been far away from people's lives, has been unable to meet people's diverse needs, people even wonder, do we need a role model in the end? It is obvious that people have been in a confused and flustered period, so it is more necessary to reshape the role model or image that can embody the spirit of the Times to guide people to set up the right concept and guide the development of people and social trends.

\section{The meaning of Model Education Law}

Model education method is the earliest method of education, but there is no clear concept until the 1950s, the model of education as a concept into the ranks of educational research. Speaking of model education, most of them are the same as "model education", so we cannot fully and thoroughly understand the essence of model education, and then affect the role of model education. From different perspectives, many experts and scholars have also defined model education.

Some scholars classify model education as a kind of practical purpose. "The educator, according to the physical and mental characteristics of the educated, takes the example as the carrier, exerts a purposeful, planned and organized influence on his members, and urges them to form social practice activities that conform to the moral qualities and values required by a certain society and at a certain stage. In short, model education is a social practice that uses the influence and function of model to achieve the aim of education or enlightenment." 
In the explanation of the concept of model education, it includes the factors of model, educator and educatee. Educators use the element of "model" to influence the educated, so that some of the positive spirit of the model can be reflected in the educated. In a word, model education is a kind of ideological and political education method, which can stimulate and warn people's thoughts and behaviors by modeling and publicizing model.

\section{Accurately grasp the plight of the Times in the development of Model Education}

\subsection{The time lag of the traditional "model" image}

With the development of economic globalization, great changes have taken place in China's economy, and at the same time, people's sense of consciousness has also changed. The relationship between people and people, between people and society has been changed correspondingly, people began to re-examine their social status and the pursuit of life. Re-examine and weigh the image of traditional role models. The traditional moral standard of "selflessness" and "special benefit to people" is no longer a unified standard. People's choices are diversified, and different types of models naturally appear. But people's choices tend to be more personal than collective, more personalized than standardized. Now we pursue personal and social unity, model and needs, willing to pay personal strength for the community, but also the pursuit of social return. This kind of pursuit does not accord with the original intention of model education to a certain extent, but the existing social reality needs to be solved urgently. But the traditional model is no longer suitable for the needs of the people at present, deviates from the reality of our country's Socialist market economy, and belittles the needs of people's inner interests, did Not reflect the socialist moral construction and economic development, failed to give a new connotation of the Times.

\subsection{The impact of values of diversity on model education}

With the rapid development of Internet, the value goal of the whole society tends to diversify, and the selectivity, independence and difference of people's thoughts are gradually strengthened, especially the subject consciousness. "people-oriented" concept has gradually taken root in the hearts of people. People no longer identify with the "example" set by others from the heart, and are used to asking "why? Why?" Everyone has their own set of standards to set an example, leading to the example of diversity, populism, idolisation. However, the traditional model-building tends to be of a single type, and the characters are too perfect to meet the needs of people's diversified value choices, which has been questioned and even denigrated. For example, the "don't let Liu Hulan get into elementary school textbooks" incident on the Internet has aroused heated discussion among netizens. Some people said that in this peaceful era, there is no need for "heroes" of the war era, it is not necessary for children to learn from distant examples. Traditional role models have been questioned and distorted, difficult to achieve emotional resonance, psychological identity.

Model Education as a flexible means of education, its value reflects the spirit of the Times, lies in the needs of the Times. Because of the influence of multivalues, instead of disturbing people's inner thoughts, when choosing a role model, easy to follow, or directly refuse to learn from others. Today is an era of peace, but also an era of globalization and fierce competition. Therefore, we should pay attention to dig around people, pay attention to the merits of different people, learn from others, balance and establish their own selection criteria.

\subsection{Excessive stereotyping of "model" propaganda}

"Model" is supposed to exist in people's real life, people can learn from the model, but in recent years, the effect of model education is not satisfactory. First of all, in the propaganda process of the model, the model was mythologized, unreal. The model is more and more remote from people's real life, and the over-perfection has only weakened the educational function of the model itself, which makes the educatee's credibility to the model greatly weakened. This in turn makes some people interested in overturning the role model, through the network of human flesh search, mining and expand the shortcomings of this character, educational purposes counterproductive. Secondly, for example of the propaganda more than fine, and gradually weakened the sustainability. In spite of our efforts in recent years to create a "model", but the effect is regrettable. The public soon forgot the specific people and things, such as: The annual moving Chinese characters, in everyone know the deeds of moving people, moved, exclamation. But in the blink of an eye to be replaced by other information and events, and forget the touching heroic deeds, then, the effectiveness of model education 
will be reflected? Will the purpose of the example be achieved. All these are the problems existing in the process of model propaganda, which are worth us to ponder over and explore.

Finally, an important reason for the continued decline in role model education is the lack of depth in the promotion of role models, most of which are too formalized or just word of mouth, the spirit of the model is not deep into people's bone marrow, the quality of the model is not internalized into individual moral quality. For example: March 5 is "Learn Lei Feng Day", various universities, enterprises and so on are learning Lei Feng Spirit, but, "Urumqi daily" has done the related investigation to some schools, but discovered that the student only knew "Lei Feng", lei Feng's story, his specific spirit, is not well understood. When asked who Lei Feng was, a student responded with a lyric: "We're all from the northeast, we're all from the northeast. Lei Feng... Lei Feng, isn't that the northeast?" And so Lei Feng became a simple symbol, the essence of Lei Feng's spirit did not play the role of model education.

\section{Remold the development path of model education in reason}

\subsection{Endow model education with new connotation of the Times}

Example education should deepen the connotation of example, dig into the spirit of advanced example, especially develop the element of example in the network space. First, the continuation of the traditional model of the spiritual connotation. Although with the development of the Times, the traditional model image seems to be a bit "out of date", but we must not arbitrarily use the changes of the times to deny the role of the model. The profound ideological essence of the hero and the lofty moral character of the model are the powerful spiritual force for us to carry out socialist modernization and overcome difficulties and challenges, and are our eternal spiritual wealth. Second, highlight the spiritual connotation of role models in the new era. The establishment of the model in the new era cannot be limited to the propaganda of some words and deeds of the advanced model, the most important thing is to enable the individual to grasp the ideological essence and essence of the advanced model. If model education, education is limited to the imitation of specific examples of model, then education will be mere formality. This not only leads to the narrow scope of education, educational content superficial, and educational effect will not be long.

\subsection{Enhancing the adaptability of model education to the era of pluralism}

First, the age of diversity requires diversity of role models. Set an example to both the moral level of the model, but also to have talent, business model. If the modern society merely sets an example by virtue, it is easy to stifle individuality, suppress creativity, make the standard of measuring people simple and stereotyped, and the standard of selecting people one-sided, which is not conducive to the diversified development of the society from various angles, it's not good for character.

Second, the era of diversity requires multiple levels of role models. Comrade Deng Xiaoping once argued that different moral standards should be applied to different people, communist moral requirements to advanced figures, and socialist moral requirements to the majority of the people. We need to set different levels of role models, to fit different levels of people, and that requires combining the different needs of people with the individual differences of role models, so that each group and each individual has their own role models.

Third, the era of diversity requires a multidimensional model. The way in which the real society exists endows people with the unique spiritual character and temperament of their time. Under the background of market economy, people pay close attention to their own interests, and consciously exert and reserve all their energy to struggle for them unremittingly. This kind of "modern personality" is the symbol of the cultural spirit of an era, it's also a basic platform for people to connect with each other. The role models also embody and bear the value pursuit of the Times. Therefore, the role models we set can not be limited to "contribution" and "selfless" role models, still can choose" struggle model", , maintain lawful rights and interests model". Multi-dimensional model more in line with the development of society and individual reality, but also will play a more effective role in guidance.

\subsection{Enhancing the internalization of the spirit of role models}

First, create real and vivid role models. The practice has proved that in the past, the model education in our country appeared the phenomenon of arbitrarily raising and mythologizing the model image, which not only 
did not enhance the effect of the model education, but made people doubt or even deny it. Therefore, model education should unselfishly show the advanced deeds and noble sentiments of model, and can not be partial and comprehensive, exaggerated. Second, model education should pay attention to individual development. Our country's model education has been the positive indoctrination education, which is very necessary for the establishment of correct social values and moral values. Today, in a new era of multicultural values and diverse personalities, independence and autonomy are seen as essential to the development of the individual and society. If our model education ignores society and individual characteristics, if we can not enter an open and dynamic development process in time, it will greatly affect the enthusiasm of individual learning, and the educational effect will not be ideal. According to psychologist Bandura's social learning theory, the construction of thought and action is a "balanced" pro- cess, an "interactive agent" rather than an individual's passive acceptance of social influences. It emphasizes that "individuals can actively choose their living environment". This is beneficial to the model education of our country in the new period. Especially in providing positive role models to young people, we should first let them choose and learn the way of thinking.

\section{References}

[1] Wen JJ. A study on the contemporary value and realization of model education[D]. Hebei: Hebei Normal University, 2010.

[2] Yang T. Model Education Research[D]. Wuhan: Wuhan University, 2010.

[3] Complete works of Marxism Friedrich Engels (volume 3)[M]. Beijing: People's Publishing House, 2002.

[4] Wu YQ. The countermeasure research of example education guiding the idolatry of middle school students. Jiangxi Normal University[J]. 2020(6). 